\title{
Working
}

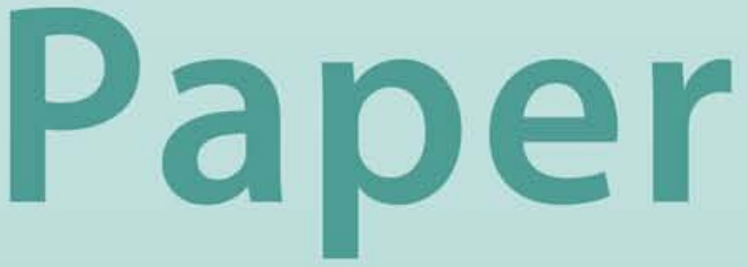




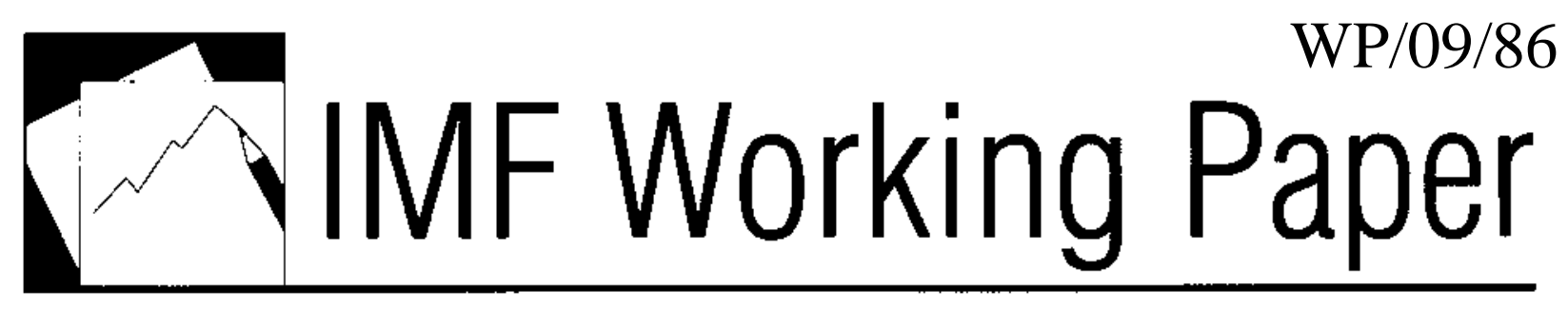

\section{Why Inflation Targeting?}

Charles Freedman and Douglas Laxton 


\title{
IMF Working Paper
}

\author{
Research Department
}

Why Inflation Targeting?

\section{Prepared by Charles Freedman and Douglas Laxton ${ }^{1}$}

Authorized for distribution by Charles Collyns

April 2009

\begin{abstract}
This Working Paper should not be reported as representing the views of the IMF. The views expressed in this Working Paper are those of the author(s) and do not necessarily represent those of the IMF or IMF policy. Working Papers describe research in progress by the author(s) and are published to elicit comments and to further debate.

This is the second chapter of a forthcoming monograph entitled "On Implementing Full-Fledged Inflation-Targeting Regimes: Saying What You Do and Doing What You Say.” We begin by discussing the costs of inflation, including their role in generating boom-bust cycles. Following a general discussion of the need for a nominal anchor, we describe a specific type of monetary anchor, the inflation-targeting regime, and its two key intellectual roots-the absence of long-run trade-offs and the time-inconsistency problem. We conclude by providing a brief introduction to the way in which inflation targeting works.

JEL Classification Numbers:E30, E31, E58

Keywords: Inflation Targeting, Monetary Policy

Author’s E-Mail Address: cfreedma@connect.carleton.ca; dlaxton@imf.org

\footnotetext{
${ }^{1}$ Charles Freedman is Scholar in Residence in the Economics Department, Carleton University, Ottawa, Canada. Douglas Laxton is the Head of the Economic Modeling Unit of the IMF's Research Department. This paper represents the second chapter of a manuscript that is being prepared by Charles Freedman, Douglas Laxton and Inci Otker-Robe On Developing a Full-Fledged Inflation Targeting Regime: Doing What You Say and Saying What you Do. The authors wish to thank a large number of colleagues at the Fund and other policymaking institutions for encouraging us to do this work. We also gratefully acknowledge the invaluable support of Heesun Kiem and Susanna Mursula for their research assistance, and Laura Leon for her help in the preparation of the paper. The views expressed here are those of the authors and do not necessarily reflect the position of the International Monetary Fund. The model simulation programs used in this paper can be downloaded from www.douglaslaxton.org. Correspondence: cfreedma@connect.carleton.ca; dlaxton@imf.org.
} 


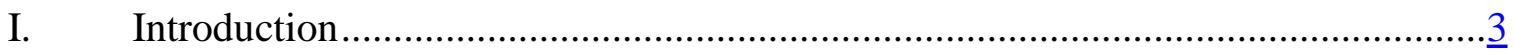

II. Cost of Inflation and Boom-Bust Cycles …......................................................

A. What Are the Costs of High Inflation? .......................................................

B. Policy Credibility and Boom-Bust Cycles …...............................................

III. Need for A Nominal Anchor......................................................................

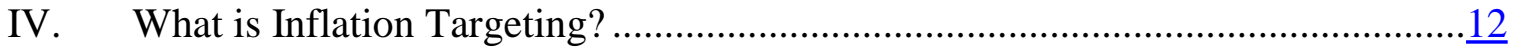

V. Two Key Intellectual Roots of Inflation Targeting...........................................13

A. Absence of Long-Run Trade-Offs ........................................................13

B. The Time-Inconsistency Problem ...........................................................19

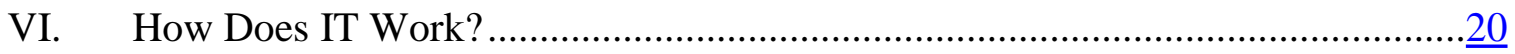

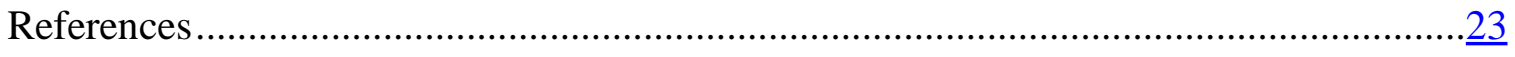

Box 2.1

1. Six Principles of Inflation Targeting...............................................................

Figures

1. United Kingdom Inflation, Unemployment and Policy Credibility.......................

2. Output-Inflation Tradeoffs in the Short Run and Long Run...............................14

3. IRFs for a Positive Demand Shock Under Good and Bad Monetary Policy ..........17

4. IRFs for a Positive Supply Shock Under Good and Bad Monetary Policy ............17

5. Taylor Output-Inflation Efficiency Frontiers...................................................19

Tables

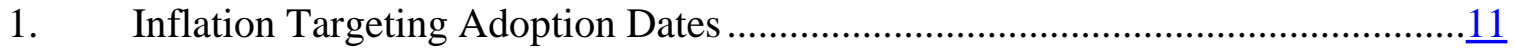

2. Reduced-Form Inflation Equations Under Good and Bad Monetary Policy .......... $\underline{18}$ 


\section{Introduction}

Over the last two decades, there has been a marked reduction in the rate of inflation in both industrialized and emerging economies, and a commitment on the part of the monetary authorities in these countries to maintain inflation at a low level. In large part, these developments are a reflection of the widespread recognition of the negative repercussions on economies of high rates of inflation and boom-bust cycles. For many advanced economies this recognition itself reflected the deleterious results of the Great Inflation of the period from the latter half of the 1960s into the early 1980s, and the contrast with the better results during the subsequent Great Moderation, especially since the early 1990s. The high and volatile rates of inflation in most countries over the earlier period were accompanied by high variability in output and unemployment and by low growth in productivity and potential output. While not ascribing all of the problems of this earlier period to the high rates of inflation, many economists came to the conclusion that an inflationary environment is very detrimental to the functioning of the economy.

This chapter examines a number of issues related to the recommitment of the monetary authorities in most countries in the recent period to achieving and maintaining a low rate of inflation. The chapter begins with a discussion of the costs of inflation, the main element underlying the view that a high inflation environment is unlikely to be conducive to a well-functioning economy. It then turns to the need for an economy to have a nominal anchor. As an introduction to the rest of this volume, it then sets out the intellectual roots of inflation targeting and briefly discusses what IT is and how it works.

\section{Costs of Inflation and Boom-Bust Cycles}

Underlying the view that monetary policy should aim at low inflation as its contribution to a well functioning economy is the proposition that there are many costs that flow from an environment of high inflation. The theoretical and empirical analysis of the costs of inflation typically compares outcomes in economies with low inflation and those with high inflation. The quantitative definition of low inflation can differ between industrialized countries and emerging economies, but clearly falls into the single digit levels in both cases, and is typically defined as low single digits for industrialized countries. For economies with hyperinflation (high triple-digit inflation and above), there are important costs in addition to those to be discussed shortly, including the shift away from domestic currencies to foreign currencies for transaction purposes. Also, some of the costs described below may not hold in the same way if the economic institutions of the country are highly indexed. 


\section{A. What Are the Costs of High Inflation?}

One of the most serious costs of high inflation involves its effect on longer-term decisions by savers and investors. Because these decisions are based, among other things, on future prices, they require a decision maker to act on the basis of expected price movements. Empirically, high rates of inflation are associated with more volatile rates of inflation. In such circumstances, if a decision maker finances a long-term project with long-term debt, it is exposed to the risk of losses in the case of an unexpected disinflation, and if it finances the project with short-term debt, it is exposed to funding risk. These risks will make decision makers less likely to invest in a project that is otherwise viable.

Moreover, among the common concomitants of periods of inflation are unrealistic expectations as to the continuation of high rates of inflation on asset prices for some time into the future. This tends to lead to bubbles in asset prices. For example, households may purchase houses and investors may purchase nonresidential real estate at prices that turn out later to have been overvalued. This is not to argue that asset price bubbles occur only at times of inflation. Rather, they are more likely to occur at such times because of the increased difficulty in evaluating future asset price developments in such circumstances.

The effect on investment decisions of inflationary distortions will result in the capital stock being smaller and/or less productive than otherwise would have been the case. The level of potential output will thus be negatively affected by periods of high rates of inflation.

Moreover, there is a literature suggesting that the distortions associated with inflation may not simply cause a decline in the level of potential output, but could also result in a decline in the growth rate of potential output. In particular, the relationship between inflation and output growth has been found to be nonlinear, with a threshold level of inflation above which inflation exerts a negative effect on growth, but below which it has no effect on growth. For example, Khan and Senhadji (2000) find the threshold to be 1-3 percent for industrial countries and 7-11 percent for developing countries, with a very wide confidence interval for the latter ( $1 \%$ to $20 \%$ confidence interval at a $90 \%$ confidence region).

A further cost of inflation derives from the distortion of relative prices during times of high inflation. Price changes are not synchronized as firms change prices at different times. Hence, relative prices will frequently not reflect relative costs of production and there will be welfare losses as consumers and producers respond to distorted relative prices and make less-than-optimal decisions.

The interaction of inflation and taxation gives rise to another notable cost of inflation. Most tax codes are based on the assumption of price stability. That is, they do not take into account the impact of inflation on financial statements. In the case of the corporate income tax, this shows up most importantly in the treatment of depreciation, inventory valuation, and interest 
costs. Since depreciation for tax purposes is based on the original cost of the capital assets, it underestimates the reduction in value over time in current dollars of the asset in question, thereby overstating profits and corporate taxes. Use of historical costs in determining the cost of goods that were sold during the current period but had been produced in earlier periods and held in inventory will also result in an overstatement of profits and corporate taxes. On the other hand, during inflationary periods, interest paid on corporate debt includes both the real interest rate and an inflation premium. While the latter is permitted as a deduction for tax purposes, in economic terms it is effectively the offset of the capital gains on machinery and equipment, which are not included in income. Hence, permitting the inflation premium as a deduction results in an understatement of income for tax purposes. Overall, these various overstatements and understatements in income may wash out for a given firm or for the economy as a whole. However, it is likely that some firms will be overtaxed and others undertaxed as a result of these inflation-induced effects on taxes, and consequently that there will be distortions in investments as firms seek to maximize their after-tax profits. In the case of the individual income tax, the most important distortion arises from the taxation of the premium for expected inflation. The latter is not really income but simply the compensation for the expected capital loss on financial assets from inflation.

It is not only the tax code that assumes price stability. Both the accounting framework and the legal framework of advanced economies are based on this assumption. And a number of financial instruments are also structured on such an assumption. Consider the standard long-term mortgage with a fixed nominal monthly payment. At a time of stable prices, nominal monthly mortgage payments are also fixed in real terms for the life of the instrument. However, during even moderate inflations, the payment in real terms is very much higher in the early years of the mortgage than in its later years. This tilt in real mortgage payments makes it much more difficult for first-time homeowners to purchase a home during periods of high inflation and high nominal interest rates. For example, the initial monthly payment on a 30 -year mortgage with 5\% real rate and 10\% inflation (i.e., approximately $15 \%$ nominal interest rate) is approximately three times the initial monthly payment on a mortgage with the same real rate and no inflation.

In long-term bond markets, nominal interest rates are equal to the sum of the long-term real interest rate, the expected rate of inflation over the term of the instrument, and a risk premium related to inflation uncertainty. The more uncertain is the future rate of inflation, the higher will be this uncertainty risk premium, and the higher will be the real cost of borrowing even if expectations of future inflation turn out to be correct. This in turn will affect aggregate investment in the economy. Conversely, as the rate of inflation falls and remains at low levels, and as inflation expectations become more anchored as a consequence, the risk premium declines and hence the real cost of borrowing declines.

There can also be important distributional consequences of inflation. At 5\% inflation, 
individuals who retire at age 60 with a nominal (unindexed) pension will lose half the value of their pensions by age 74 and three-quarters of the value of their pension by age 88 . And lower income individuals will find it more difficult to protect themselves against the effects of inflation on their savings and perhaps on their incomes than will higher income individuals.

Even those who are able to protect themselves against inflation (for example, by the use of certain types of financial instruments or by shifting into real assets from financial assets) may find it costly to do so. Clearly, from the perspective of the economy as a whole, resources diverted from real consumption and/or real investment in order to protect against the ravages of inflation are socially wasteful even if they are privately optimal.

Labor negotiations are typically more arduous at times of high inflation because of the uncertainty surrounding the future rate of inflation. Unions will want to protect their members against the possibility of a further increase in the rate of inflation over the term of the contract. Employers, on the other hand, will be concerned that entering into a collective agreement that assumes a continuation of the current rate of inflation will be very costly to them if the rate of inflation declines during the life of the contract. Hence, negotiations tend to be much more difficult at a time of uncertainty about the future rate of inflation than when the latter is more predictable. Empirically, as noted earlier, high rates of inflation are associated with high inflation volatility. It is therefore not surprising that days lost to strikes are typically larger at times of high inflation than at times of low and more predictable inflation, when negotiations can focus on real wages since both sides are more or less agreed on the future rate of inflation.

\section{B. Policy Credibility and Boom-Bust Cycles}

Another potential implication of high and volatile inflation relates to output and unemployment volatility. While the business cycle is a phenomenon that characterizes the economy of all countries with market-oriented economic arrangements, the amplitude of the business cycle can be significantly affected by the distortions caused by inflation. As the experience of earlier bouts of inflation in the postwar period and developments in the period between mid-1960s and the early 1980s (the Great Inflation) have shown, sharp downturns in the economy typically follow upsurges in inflation, as the price distortions caused by inflation lead initially to bouts of overinvestment followed subsequently by bouts of underinvestment. The more serious the distortion caused by inflation, the larger is likely to be the decline in aggregate demand once the upward pressures on inflation diminish or reverse. Moreover, in countries that conducted macroeconomic policies on a stop-go basis, shifting between expansionary policies at times of low inflation and contractionary policies at times of high inflation, policy actions induced an inefficient amount of output and unemployment variability. The high volatility of output and unemployment in the period of high inflation and its decline in the period of inflation moderation suggest that the two phenomena are closely 
associated. A concrete example in this regard is Canada, which suffered from sharp declines in output and increases in unemployment in the early 1980s and again in the early 1990s, in each case following upward pressure on inflation, but faced only mild cyclical movements after the taming of inflation. And the United Kingdom, which had a very high amplitude of unemployment variability through much of the postwar period, has recorded a much smoother path for unemployment since it achieved low rates of inflation and was successful in anchoring long-term inflation expectations - see Figure 1.

Figure 1: United Kingdom Inflation, Unemployment and Policy Credibility
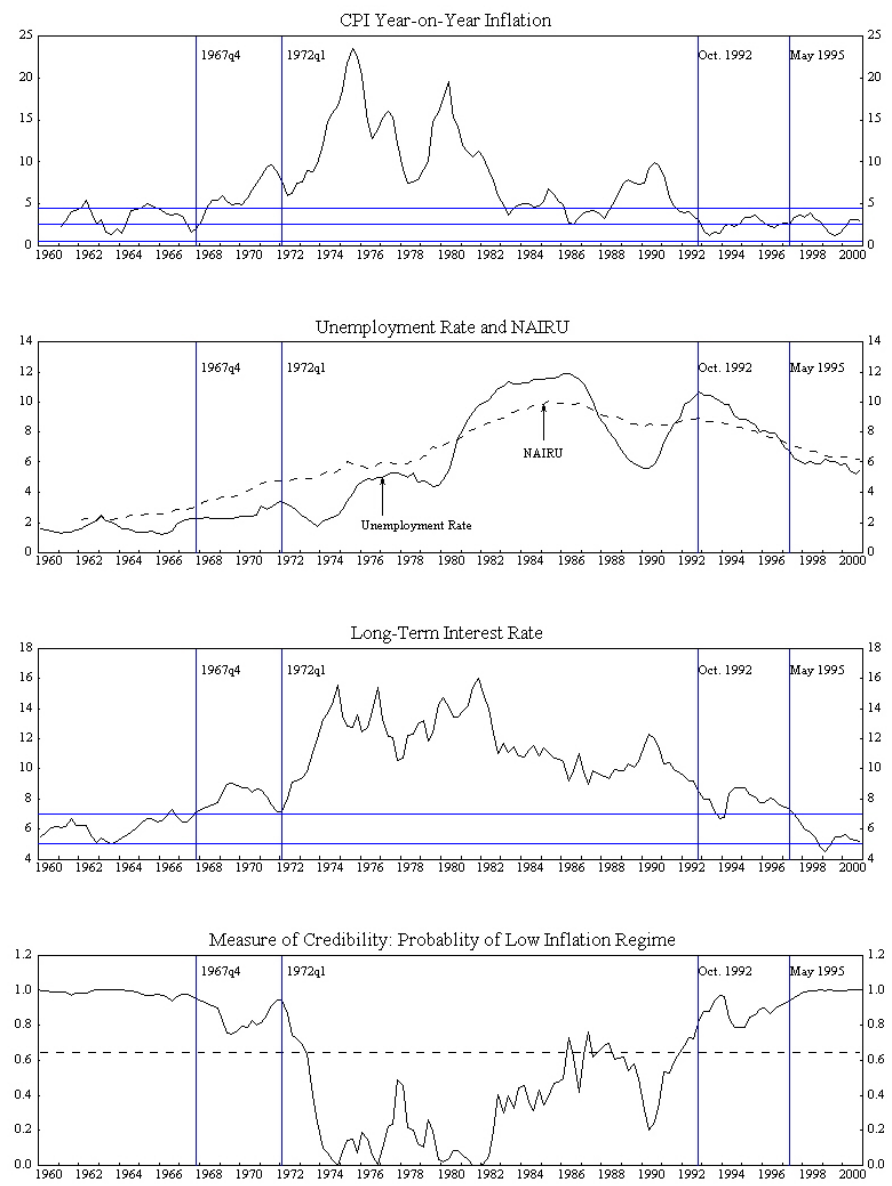

Kumhof and Laxton (2007) provide a full-blown model-based assessment for the United States on how much of the improved performance in macro variability can be accounted for by better macro policies. They conclude that better macro policies were an important element, representing about $50 \%$ of the overall improvement. ${ }^{2}$ These results are in sharp contrast with

${ }^{2}$ It is important to emphasize that while the United States is not a formal IT country because it lacks a well- 
those of a study by Stock and Watson (2003), which argued that more efficient monetary policy does not account for much of the improvement in output variability in the recent period relative to that of earlier periods, such as during the 1970s and early 1980s (i.e., during the Volcker disinflation). The problem with the Stock and Watson (2003) analysis is that it fails to recognize the length of time it takes to re-anchor long-term inflation expectations once credibility in a low inflation regime has been lost, and hence does not attribute the reduction in economic volatility to improved policy because it occurred with a lag. Indeed, as shown by Laxton and N'Diaye (2002) this process took several years in most countries, and only happened once a sufficient track record on inflation had been established along with other supporting policies (fiscal, labor market and product market policies) that made the objectives of monetary policy easier to achieve. ${ }^{3}$ That said, discussions about the logic behind the pursuit of low inflation and the adoption of IT may actually contribute to the overall reform agenda by creating greater awareness of the limitations of monetary policy and refocusing attention on those policies that have a much better chance of achieving real objectives, such as lower unemployment. The charts of policy credibility, inflation and unemployment in the United Kingdom in figure 1 illustrate the lags between the adoption of inflation targeting in 1992 and the build up in credibility, the decline in long-term interest rates and the decline in the NAIRU.

\section{Need for A Nominal Anchor}

In their pursuit of low inflation as the best contribution that monetary policy can make to a well-functioning economy, central banks have typically relied upon a nominal anchor as the basis for their monetary policy. A nominal anchor is considered useful to central banks in conducting monetary policy in a number of dimensions. It helps clarify both within the central bank and to the general public the (intermediate or final) objective of the central bank in carrying out policy. Thus, in the internal deliberations of the central bank, it helps to focus attention on the central objective, and prevents situations in which the members of the monetary policy decision-making body are aiming at very different objectives. A publicly announced policy anchor also helps the central bank to communicate externally both its policy goals and the reasons for changes in its policy instrument. Finally, a credible nominal anchor

defined numerical inflation objective, the differences between the United States and the most advanced full-fledged IT countries is small, given its high levels of operational transparency. In addition, while goal transparency is a bit lower in the United States it is clear based on historical performance and communications that the Federal Reserve is committed to keeping inflation low and stable. For evidence on the benefits of IT in Canada see Longworth (2002).

${ }^{3}$ This is the Third Principle of IT listed in Box 2.1 later in this chapter. An important implication of this principle is that we should be cautious not to exaggerate the role of IT in bringing about improvements in macro stability when other significant reforms contributed to reducing unemployment, raising potential output and increasing competition and flexibility of labor and product markets. For a discussion of the implications of these policies on the monetary transmission mechanism see Bayoumi, Laxton and Pesenti (2004). 
helps focus the expectations of the public on the policy goal, and thereby facilitates the achievement of the goal. Thus, in countries where the final goal of monetary policy is a low rate of inflation (whether aimed at directly or via an intermediate target), policy success helps to anchor long-term inflation expectations on the target.

Historically, the most common nominal anchor involved linking the value of the domestic currency to gold (under the gold standard) or to a major currency, such as the pound sterling or the US dollar (under the gold-exchange standard). While some form of fixed exchange rate was the principal nominal anchor in the first two to three decades of the postwar period, the collapse of Bretton Woods and the sharp increase in worldwide inflation in the first half of the 1970 s led to a search in industrialized countries for an alternative nominal anchor. Many countries tried to anchor their monetary policy by targeting a monetary aggregate, in the expectation that controlling the rate of growth of money would enable them to bring down the rate of inflation and maintain it at a low level. Unfortunately, money targeting proved unsuccessful for a number of reasons, the most important being a lack of stability in the demand for money function. This instability was largely the result of a combination of deregulation (in some countries) and a wave of financial innovation by banks and other financial entities that resulted in important changes in the way that the public held their financial assets, significantly affecting the various measures of money.

By the mid-1980s, it was clear that monetary targeting had failed as a nominal anchor for central bank policy. In some countries that had earlier adopted a floating exchange rate, the inability to use either of the traditional nominal anchors (fixed exchange rate and monetary aggregate targets) left a vacuum, which was sometimes filled by a qualitative commitment to low inflation on the part of the central bank. For those countries that had a history of high and volatile inflation, such an arrangement was insufficient to convince the general public that the central bank was truly committed to taking the actions necessary to bring down the rate of inflation and to maintain it at a low level. In those countries (initially New Zealand and Canada), the explicit commitment to a quantitative path for future inflation was seen as a mechanism that would help the central bank succeed in achieving its objective of bringing about and maintaining a lower rate of inflation.

In the first half of the $1990 \mathrm{~s}$, a number of other countries also had unfavorable experience with exchange rate targets. For example, the United Kingdom, Sweden and Finland, which had been using a fixed exchange rate as their policy anchor and as a way of achieving the same low rates of inflation as the country to which they had tied their currency, found themselves forced by market pressures to abandon the fixed exchange rate. In some cases (e.g., the United Kingdom) they had an earlier unsuccessful experience with monetary targeting. Since they could no longer use the fixed exchange rate as the anchor for their policy and since their monetary aggregates were insufficiently stable to serve as the basis of policy, they chose to introduce inflation targeting as the central element of their policy framework. 
Later in the decade, the new approach to policy spread to emerging economies. Many of these countries had also been forced off fixed exchange rates by market pressures. While there is some debate in the literature as to the starting point of IT in some of these countries, in practice none of them gave clear priority to inflation targeting over their exchange rate objective until the second half of the 1990s.

Thus, the circumstances surrounding the adoption of IT have differed across countries. In virtually all cases, however, the adopting country had a history of relatively high rates of inflation and used the framework as a way of achieving and/or maintaining a lower rate of inflation. In some cases, such as New Zealand and Canada, the move to IT was not crisis driven and resulted from a decision that this was the best framework for achieving price stability in countries that were operating under flexible exchange rates and whose monetary aggregates were unstable. In other countries, such as the United Kingdom, Sweden, and Brazil, the adoption of IT followed the forced exit from a fixed exchange rate regime. With the loss of the exchange rate anchor and in circumstances where monetary aggregates were unstable, the IT framework remained as the sole available mechanism. In yet other countries, such as Israel and Chile, inflation targeting coexisted for some period of time with some form of exchange rate target, and only gradually was there a decrease of emphasis on the exchange rate anchor and a concomitant increase of emphasis on IT.

What is the current situation regarding nominal anchors? No industrialized country is currently using a monetary aggregate as its policy anchor and there is little likelihood that the situation will change in the future. As far as exchange rate anchors are concerned, the large majority of industrialized economies are on a flexible exchange rate regime or are part of a monetary union in which the central bank of the monetary union (the European Central Bank) floats its currency. Many, but not all, of these countries use an IT framework as the basis of their policy. Others, such as the United States and Japan, are committed to low inflation but use a more qualitative approach and do not have an explicit quantitative target for the rate of inflation.

The situation in emerging economies is more varied. Some still use monetary aggregates as a policy anchor, perhaps because they feel that no other option is available or feasible. (Some of these do not yet have the capacity to implement an IT regime.) Others use some form of fixed exchange rate. In some cases, especially smaller economies, they use harder versions of the fixed exchange rate regime, involving the use of another country's currency for much of their transactions (dollarization or euroization), a currency board, or participation in a monetary union. In other cases, a softer version of the fixed exchange rate regime, involving some variant of the classic adjustable peg, with or without fluctuation margins, is still used. Several emerging economies, typically midsized or larger, have adopted an IT framework and are using IT as their nominal anchor-see Table 1 for the list of countries that have adopted IT as 
well as their adoption dates. ${ }^{4}$

Table 1: Inflation Targeting Adoption Dates

\begin{tabular}{lccc}
\hline & Year & $\frac{G D P}{P O P}$ & Publish Endogenous Interest Rate Forecast \\
\hline 1. New Zealand & 1990 & 0.57 & Yes \\
2. Canada & 1991 & 0.83 & \\
3. United Kingdom & 1992 & 0.76 & Yes \\
4. Sweden & 1993 & 0.79 & \\
5. Finland** & 1993 & 0.74 & \\
6. Australia & 1993 & 0.78 & Yes \\
7. Spain*** & 1995 & 0.65 & \\
8. Israel & 1997 & 0.55 & \\
9. Czech Republic & 1998 & 0.50 & \\
10. Poland & 1998 & 0.34 & \\
11. Brazil & 1999 & 0.21 & \\
12. Chile & 1999 & 0.30 & \\
13. Colombia & 1999 & 0.14 & \\
14. South Africa & 2000 & 0.21 & \\
15. Thailand & 2000 & 0.17 & \\
16. Korea & 2001 & 0.52 & \\
17. Mexico & 2001 & 0.28 & \\
18. Norway & 2001 & 1.14 & \\
19. Iceland & 2001 & 0.84 & \\
20. Hungary & 2001 & 0.41 & \\
21. Peru & 2002 & 0.16 & \\
22. Philippines & 2002 & 0.07 & \\
23. Slovak Republic & 2005 & 0.41 & \\
24. Indonesia & 2005 & 0.08 & \\
25. Romania & 2005 & 0.24 & \\
26. Turkey & 2006 & 0.27 & \\
27. Ghana & 2007 & 0.03 & \\
\hline & &
\end{tabular}

${ }^{4}$ This list is based on an update of the adoption dates reported by Roger and Stone (2005). While these dates are the ones that are typically referred to in many studies, it is important to emphasize that many of these countries started with very simple versions of IT and then improved their frameworks over time-see Batini and Laxton (2007). The adoption dates in Chapter 10 are based on the view of the national authorities and differ from those in this table for Chile and Israel. 


\section{What Is Inflation Targeting?}

What are the principal characteristics of IT? Different authors provide somewhat different lists, but the basic thrust of these lists is similar. For example, Bernanke and others (1999) assert that inflation targeting is a framework for monetary policy characterized by (i) the public announcement of official quantitative targets (or target ranges) for the inflation rate over one or more time horizons, and (ii) the explicit acknowledgment that low, stable inflation is monetary policy's primary long-run goal. Among other important features of inflation targeting are (iii) vigorous efforts to communicate with the public about the plans and objectives of the monetary authorities, and, in many cases, (iv) mechanisms that strengthen the central bank's accountability for attaining those objectives. Mishkin (2007) defines inflation targeting in much the same way but adds one more element - that inflation targeting is an information inclusive strategy in which many variables, and not just monetary aggregates or the exchange rate, are used for deciding the setting of policy instruments. He goes on to say that the list of characteristics of IT should clarify one crucial point: it entails much more than a public announcement of numerical targets for inflation for the year ahead. This is important in the context of emerging market countries because many of them routinely report numerical inflation targets or objectives as part of the government's economic plan for the coming year, and yet their monetary policy strategy should not be characterized as inflation targeting, which requires the other elements for it to be sustainable over the medium term.

While the above definitions are based on so-called full-fledged IT (FFIT), some emerging economies have used "lighter" versions of IT, either as preparation for FFIT or because of concerns about the implications of committing themselves to FFIT_-see Stone (2003). These lighter versions might involve continuing some element of exchange rate targeting in addition to inflation targeting, or being less transparent in their communications strategy than is typical for full-fledged inflation targeters. Chapter 5 of the volume will examine some of conditions that facilitate the successful functioning of IT in emerging economies and how not fulfilling such conditions affects the functioning of the IT regime ${ }^{5}$ Box 2.1 provides a brief summary of Six Basic Principles of IT Regimes, which can be very useful in evaluating performance and designing the framework that is used to promote high levels of operational transparency and accountability.

\footnotetext{
${ }^{5}$ See Freedman, Laxton, and Otker Robe (2009).
} 


\section{Box 2.1: Six Principles of Inflation Targeting}

The design, implementation and evaluation of IT regimes can usefully be guided by the following six key principles.

1. The primary role of monetary policy is to provide a nominal anchor for the economy and placing weights on other objectives must not be inconsistent with providing an anchor for inflation and inflation expectations.

2. An effective inflation-targeting regime will have beneficial first-order effects on welfare by reducing uncertainty, anchoring inflation expectations and reducing the incidence and severity of boom-bust cycles.

3. The success of an IT regime depends on other policies that make the task of monetary policy easier and more credible.

4. Because of the lags in the monetary transmission mechanism, and because of the concern with both the deviation of inflation from its target and the deviation of output from potential, it is neither possible nor desirable to keep inflation exactly on target and in practice inflation targeting becomes inflation-forecast targeting.

5. Given the possibility of conflict between inflation targets and other objectives, central bankers must have reasonably clear objectives and sufficient independence from the political process to achieve these objectives.

6. There must be effective monitoring and accountability mechanisms to ensure that central bankers are behaving in a manner consistent with the announced underlying objectives and that monetary policy is being based on sound practices.

\section{Two Key Intellectual Roots of Inflation Targeting}

Despite the fact that IT was chosen by policymakers as a practical solution to their previous experiences with high inflation and boom-bust cycles there were two key intellectual roots to IT-first, the absence of an exploitable long-run trade-off between output and inflation, and, second, the time inconsistency problem.

\section{A. Absence of Long-Run Trade-Offs}

The first intellectual root dates back to the 1960s when Milton Friedman and Edmund Phelps argued that it was unlikely that there was an exploitable long-run trade-off between output and 
inflation — see Friedman (1968) and Phelps (1968). The basic argument was that if policymakers attempted to exploit the observed short-run trade-off between output and inflation, expectations of inflation would ratchet upwards over time and output would simply return back to its equilibrium level. This was sometimes referred to as the long-run natural rate hypothesis (LRNH), which posited that while monetary policy might have important short-run effects on the real economy, in the long run real variables like GDP were more likely to be determined by tastes and technology, and consequently there was unlikely to be an exploitable long-run positive trade-off between output and inflation.

Figure 2 provides a graphical depiction of the short-run and long-run trade-offs. Suppose inflation was initially at 2 percent with a zero output gap (point A) and policymakers attempted to exploit the short-run Phillips Curve (SRPC) by moving to point B with a higher level of the output gap. Friedman and Phelps argued that such a policy might be successful in the short run, but that over time the SRPC would shift upward until we reach a new equilibrium at point $\mathrm{C}$ with a zero output gap and even higher levels of both inflation and inflation expectations. While these basic ideas had an enormous impact in academia and provided the seeds for the rational expectations revolution in macroeconomics, the implications and insights of these basic ideas were slow to catch on in policymaking circles. What exactly were these key insights and how would they have helped to prevent some of the deleterious effects of providing excessive monetary policy accommodation in response to the supply shocks in the late 1960s and 1970s?

Figure 2: Output-Inflation Tradeoffs in the Short Run and Long Run

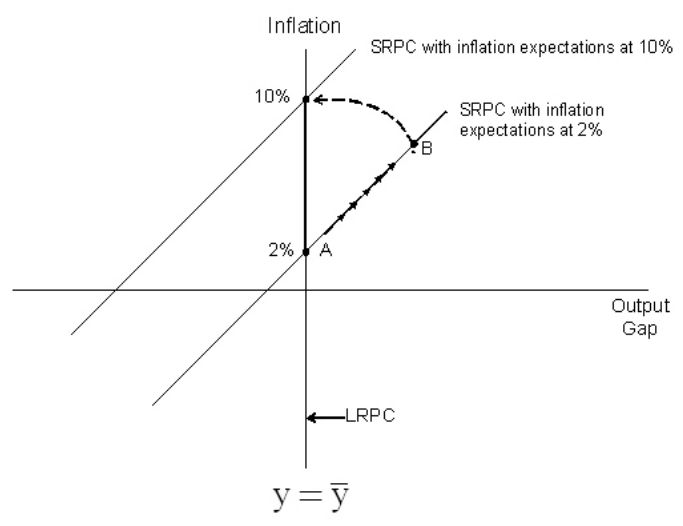

The first important insight is understanding the difference between a dynamic structural model (DSM) of the economy and a reduced-form econometric (RFE) model. To understand the difference between these two types of models, it is useful to consider the following stylized DSM representation of the output-inflation process, which consists of an inflation equation $(\pi)$ that depends on the output gap $(y)$, an output gap equation that depends on the 
real interest rate $\left(i_{t}-E_{t} \pi_{t+1}\right)$ and lagged output gap, and an interest rate reaction function where the real interest rate is related to both the output gap (y) and the deviation of inflation from target $\left(\pi_{t}-\pi^{*}\right){ }^{6}$

$$
\begin{gathered}
\pi_{t}=\lambda E_{t} \pi_{t+1}+(1-\lambda) \pi_{t-1}+\beta y_{t}+\varepsilon_{t}^{\pi} \\
y_{t}=-\gamma\left(i_{t}-E_{t} \pi_{t+1}\right)+\rho y_{t-1}+\varepsilon_{t}^{y} \\
i_{t}=E_{t} \pi_{t+1}+\phi\left(\pi_{t}-\pi^{*}\right)+\theta y_{t},
\end{gathered}
$$

In this highly stylized economy the disturbance terms $\varepsilon_{t}^{\pi}$ and $\varepsilon_{t}^{y}$ are sometimes described as supply and demand shocks because the latter generates a positive correlation between output and inflation while the former creates a negative correlation between these two variables. The DSM described by equations 1 to 3 implies that there will be a short-run trade-off between output and inflation because of the presence of lagged inflation in equation 1. However, by design the model will also incorporate the key insight of Friedman and Phelps, which is that changes in the rate of inflation will not have any sustainable effect on the level of the output gap. ${ }^{7}$

The model also incorporates an additional insight that has come to be known as the Taylor Principle, after John Taylor. ${ }^{8}$ Basically, in this simple model the parameter $(\phi)$ on the deviation of inflation from the target must be greater than 0 for the system to be stable. This is necessary to generate the necessary adjustments in the real interest rate and the output gap to ensure that the system is anchored and inflation moves gradually back to the target. In this sense the model is consistent with the First Principle of IT, which involves a commitment of the monetary authorities to adjusting the policy rate in response to new information to provide an anchor for inflation and inflation expectations - see Box 2.1 for a summary of the other principles of IT. Interestingly, as will be shown below, any time this condition is satisfied and monetary policy is successful in making inflation stationary, the reduced form of the system described by equations 1 to 3 will make it appear as if there is a long-run trade-off between inflation and output.

It is important to understand that any stable linear DSM will have a reduced-form

\footnotetext{
${ }^{6}$ For simplicity of exposition, the equilibrium real interest rate was omitted from equation 3.

${ }^{7}$ As reviewed below, the empirical evidence suggests that high levels of inflation are likely to result in a reduction in the long-run equilibrium level of output because of the distortions that they generate.

${ }^{8}$ For a discussion of monetary policy rules see Taylor (1993, 1996, 1998a, 1998b, 1999).
} 
representation where each of the endogenous variables can be expressed as a function of the state variables and disturbance terms in the system. In our simple stylized example, because there is only one lag of inflation and the output gap in the model, the reduced-form inflation equation will be of the form.

$$
\pi_{t}=\omega_{0} \pi^{*}+\omega_{1} \pi_{t-1}+\omega_{2} y_{t-1}+\omega_{3} \varepsilon_{t}^{\pi}+\omega_{4} \varepsilon_{t}^{y}
$$

For illustrative purposes assume that all the parameters of the DSM are equal to 0.5 $(\lambda=\beta=\gamma=\rho=\phi=\theta=.5)$ and that the two disturbance terms, $\varepsilon_{t}^{\pi}$ and $\varepsilon_{t}^{y}$, are normally and independently distributed with mean zero and variance equal to 1 . Table 2 reports the parameter values of the RFE model for this case ${ }^{9}$ and labels it as good monetary policy because the monetary policy feedback rule is successful in anchoring inflation and long-term inflation expectations (measured as the 40-quarter ahead model-consistent expectation of inflation $\left.E_{t} \pi_{t+40}\right)$ to the target $\left(\omega_{0}=0.40\right.$ and $\left.\omega_{1}=0.60\right)$. Note, that while the economy still contains significant inflation inertia $\left(\omega_{1}=0.60\right)$, monetary policy is successful in steering forecasts of inflation back to the target over a 4 to 6 quarter horizon in response to unit shocks to either supply or demand-see Figures 3 and 4.

Table 2 also shows an alternative case labelled as bad monetary policy where we set the coefficient on the output gap in the interest rate reaction function to zero and impose extremely weak feedback from deviations of inflation from its target to the real interest rate $(\phi=.001, \theta=0)$, and effectively just commit to adjusting the nominal policy rate one for one with the rate of inflation expected in the following period. Note, in this case that because the real interest rate barely moves in response to shocks to demand or supply, inflation has an extremely weak link to the target $\left(\omega_{0}=0.03\right)$ and the persistence in the inflation process is close to a unit root $\left(\omega_{1}=0.97\right)$. Interestingly, in comparing the two cases not only is there substantially less inflation persistence under good monetary policy, the response of inflation to shocks becomes much weaker even in the very short run-see Figures 3 and 4 . And the combination of these effects significantly reduces the variability in inflation, the output gap and our measure of long-term inflation expectations $\left(E_{t} \pi_{t+40}\right)$.

The last column of Table 2 computes the slope of the long-run trade-off (SLRPC, the slope in the long-run Phillips Curve) assuming that policymakers mistakenly assumed that the parameters in equation 4 were structural and asked how much would a permanent increase in the output gap of 1 percentage point raise inflation in the long run. These estimates in Table 2 are created by simply taking the reduced-form parameter on the lagged output gap and dividing by one minus the parameter on the lagged dependent variable. Interestingly, when monetary policy is doing its primary job and providing an anchor for inflation and long-term inflation expectations, such a calculation would suggest that there might be a significant

\footnotetext{
${ }^{9}$ The model was solved using Dynare. See Juillard (2008).
} 
Figure 3: IRFs for Positive a Demand Shock Under Good and Bad Monetary Policy
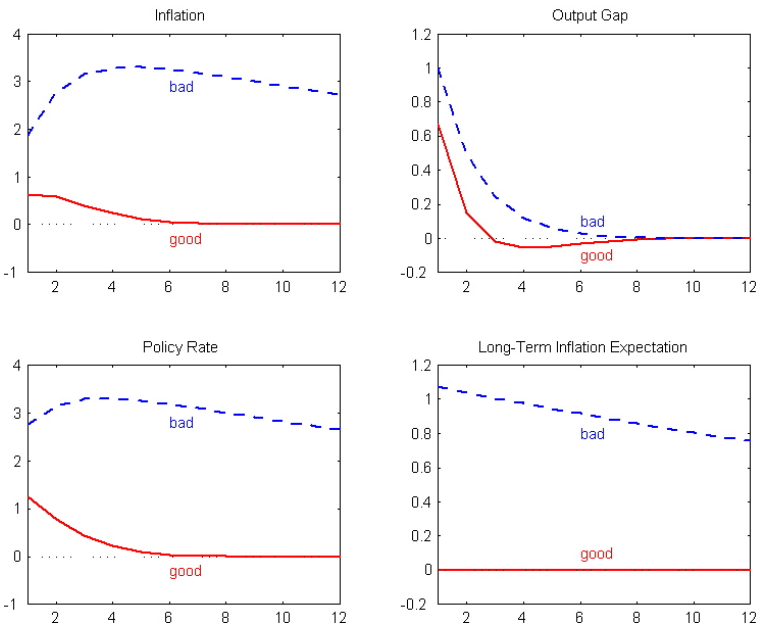

Figure 4: IRFs for Positive a Supply Shock Under Good and Bad Monetary Policy
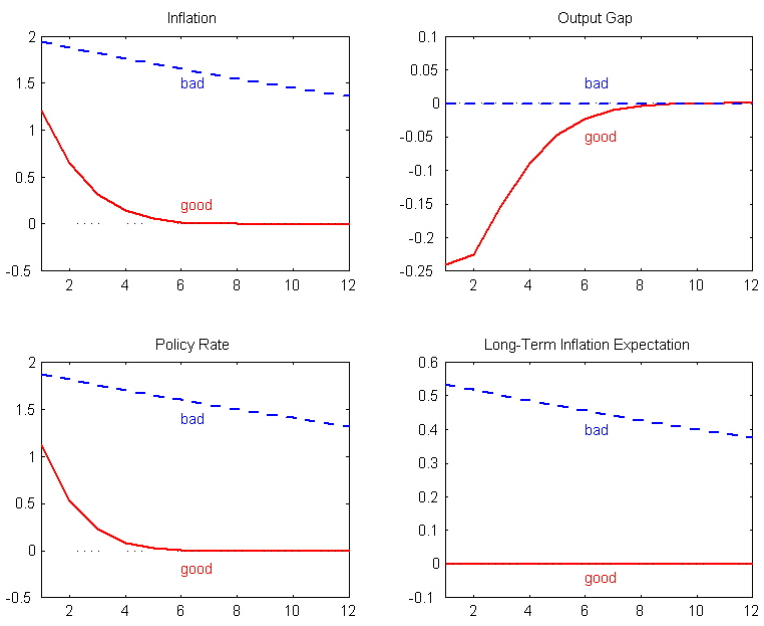
long-term trade-off between output and inflation. But when monetary policy is irresponsible and allows a large degree of persistence and variability in the inflation process there will be a perception that this trade-off is worsening. This basic problem of misinterpreting reduced-form inflation equations was pointed out by Sargent (1971), but was very slow to catch on in applied empirical work in both academia and policymaking institutions, where it was standard practice to test if the sum-of-the-coefficients in the reduced-form inflation equation were equal to $1 .{ }^{10}$ Indeed, one interpretation of the Great Inflation of the late 1960s and 1970s is that it was caused by bad methodology, or more precisely by a misunderstanding of the limitations of reduced-form econometric models for policy analysis. While Lucas (1976) provided a convincing logical case that the parameters in RFEs were likely to shift in response to changes in the policy regime, it would take years for these ideas to become firmly established in a new generation of macro policy models inside central banks. ${ }^{11}$

Table 2: Reduced-Form Inflation Equations Under Good and Bad Monetary Policy

\begin{tabular}{lccccccccc}
\hline & $\pi^{*}$ & $\pi_{t-1}$ & $\mathrm{y}_{t-1}$ & $\varepsilon_{t}^{\pi}$ & $\varepsilon_{t}^{y}$ & $\sigma_{\pi}$ & $\sigma_{y}$ & $\sigma_{\pi L T E}$ & SLRPC \\
\hline Good Monetary Policy & 0.40 & 0.60 & 0.32 & 1.20 & 0.63 & 1.73 & 0.79 & 0.00 & 0.80 \\
& & & & & & & & & \\
Bad Monetary Policy & 0.03 & 0.97 & 0.94 & 1.94 & 1.88 & 16.70 & 1.15 & 4.82 & 31.33 \\
\hline
\end{tabular}

While it is now generally accepted in policymaking circles that there is not an exploitable positive long-run trade-off between the levels of output and inflation there is clearly a trade-off between the variability in inflation and output, or what is now commonly referred to in the literature as Taylor Efficiency Frontiers (TEF). Figure 5 plots two TEFs that provide another perspective on the Great Inflation of the 1960s and 1970s and the Great Moderation over the last decade. Efficient or good monetary policies can be thought of as policies that minimize the variability in output and inflation, while bad monetary policies can be thought of as monetary policies that result in excessive variability in inflation and output. The position of

\footnotetext{
${ }^{10}$ The argument we are making here is quite general and holds even if there were more lags of inflation in the DSM.

${ }^{11}$ For a summary of the history of macro modeling in policymaking institutions see The Economist (2006). Interestingly, as late as a decade ago there was still a small group of economists in the profession that argued there was little empirical evidence that the Lucas critique has much practical relevance in spite of the fact that many central banks had already been quite successful in anchoring long-term inflation expectations and reducing the persistence in the inflation process - see Laxton and N'Diaye (2002) for some empirical evidence on the Lucas Critique.
} 
the TEF will depend on the structure of the economy as well as the magnitude and type of shocks hitting the economy. One common interpretation of the Great Inflation of the 1960s and 1970 s is that the economy experienced a series of stagflationary supply shocks that shifted the TEF outward from XX to YY, but because monetary policy responded inappropriately by providing excessive monetary accommodation actual variability increased much more than what was necessary (to z). And having learned from the mistakes in the 1960s and 1970s (either $\phi$ was too small, or the size of the output gap was underestimated, or both), policymakers have become much quicker to identify shifts in the economy's underlying capacity and have done a better job providing or removing monetary accommodation when it has been warranted.

Figure 5: Taylor Output-Inflation Efficiency Frontiers

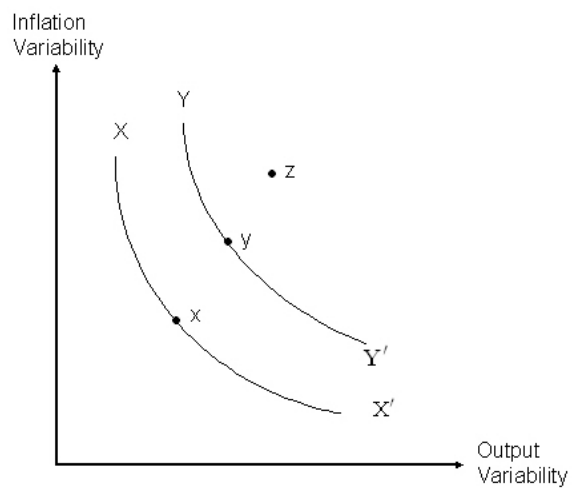

\section{B. The Time-Inconsistency Problem}

The second intellectual root behind IT was based on the time-inconsistency problem developed by Kydland and Prescott (1977) and later popularized by Barro and Gordon (1983a, b). These ideas were also based on the output-inflation trade-off, but instead of policymakers not understanding the implications of the Long-Run Natural Rate Hypothesis it was assumed that they understood it perfectly. According to this view the presence of nominal rigidities and distortions in the economy provide incentives for policymakers to exploit the short-run Phillips curve to try to achieve levels of output that are higher than potential, but such policies end up being very counterproductive as agents come to correctly anticipate higher inflation, resulting in an equilibrium with inflation bias and no long-term gains in real output. It is still subject to debate how relevant this hypothesis is for explaining the Great Inflation of the 1960s and 1970s in advanced economies like the United States, but many economists find the argument and its implications convincing for explaining the experiences 
of very high inflation countries. Subsequent work extending the basic framework resulted in a series of papers starting with Rogoff (1985), which suggested appointing conservative central bank governors with much stronger preferences for low inflation than the general public. This work was later extended in a number of papers that focused attention on creating incentives for central bankers to maintain low inflation — see Walsh $(1995,1998)$. Interestingly, these ideas featured prominently in the design of the very first IT framework in New Zealand, which consisted of a contract where the governor could be fired if inflation moved outside the band. The exact weight that should be placed on the historical inflation-bias problem remains unclear and may vary across countries, but emphasis on the importance of central bank independence combined with high levels of transparency and accountability may be a useful practical solution to the inflation-bias problem.

\section{How Does IT Work?}

How did the IT industrial country central banks envision the operation of the new framework? From the outset, these central banks practised what later came to be known as flexible inflation targeting. That is, in structuring their arrangements, they clearly took into account two objectives - first, to achieve the targeted rate of inflation, and, second, to do so in a way that would not result in excessive fluctuations in output and unemployment. This was reflected in the fact that they aimed at achieving their inflation objective over a medium-term horizon (on the order of 6 to 8 quarters in many industrialized countries) and took the position that any miss in achieving one target would be rectified only gradually over time. Effectively, the IT central banks were acting as if they had a loss function that contained two arguments the variability of the rate of inflation around its target and the variability of output around capacity. Such a loss function was central to the framework proposed by Lars Svensson in the mid-1990s in his early articles on inflation targeting — see, e.g., Svensson (1997).

It was clear from the beginning of IT that the interest rate response (and the resulting exchange rate response) to demand shocks in an IT environment would move both output and inflation in the desired direction (what Blanchard and Galí (2007) call a "divine coincidence"). For example, a temporary positive demand shock would tend to increase output above potential and subsequently raise inflation above its target rate. The interest rate increase in response to such a shock would bring demand back to potential and inflation back to target. Similarly, a negative demand shock that would result in lower output and inflation would lead to a decline in interest rates, which would tend to offset the direct effects of the shock. The close link between excess demand and future inflation, and the need to take offsetting interest rate actions in response to demand shocks, were apparent from the very beginning of the IT experience.

Supply shocks raised a much more difficult issue. Since they might well come in the form of 
an increase in inflation and a decline in output, it appeared that IT would have the same difficulty in coping with such shocks as did other policy frameworks. ${ }^{12}$ While raising interest rates would act in the direction of bringing inflation back to target following an unfavorable supply shock, it would weaken demand further. On the other hand, reducing interest rates would help underpin aggregate demand but would lead to further upward pressure on inflation. In fact, over time, as IT central banks achieved their inflation targets and as their credibility improved, they were able to cope with supply shocks much more easily than had earlier been anticipated. Even in the face of supply shocks, medium-term expectations remained anchored at or near the target rate of inflation, and consequently there was less or no need to raise interest rates in the face of a temporary supply shock. In some IT countries, the central bank facilitated the ability of the public to see through such supply shocks by emphasizing the role of a core rate of inflation as a guide to policy (since the core inflation measure eliminated the more volatile components of the CPI and hence tended to remove the effects of temporary supply shocks), and in this way clarified that price shocks that did not feed into expectations of future inflation would be treated differently from those that did.

Because of the lags between central bank actions in raising or lowering the policy rate of interest and their effect on the rate of inflation, and because of the concern with both the deviation of inflation from its target and the deviation of output from potential, the emphasis in IT is on the expected future rate of inflation, not the present rate. Current policy actions cannot affect the latter, which is the result of past policy actions and shocks. Hence, the focus in the policy debate in IT central banks is always on what the rate of inflation is expected to be over the policy horizon, a period of time by which the central bank expects inflation to return to its target following the combination of a shock and the appropriate monetary policy response. And central bank communications in the IT framework focus on the forecast rate of inflation over the policy horizon, the movements of the policy rate of interest needed to achieve the inflation target towards the end of that period, and the medium-term nature of the policy framework.

It is worth emphasizing that one of the crucial attributes of IT has been the advantage for policymaking of a situation in which medium-term expectations for the rate of inflation are anchored to the target announced by the authorities. This anchoring of expectations will result from the success of the central bank in achieving the announced target in the early years of IT, along with the transparency and communications of the central bank in explaining the way in which it operates to achieve its target. And the anchoring of inflation expectations will facilitate the achievement of subsequent inflation targets. In the case of both demand shocks and supply shocks, an increase in the rate of inflation that is not accompanied by an increase in inflation expectations requires less of an interest rate increase to bring inflation back to target

\footnotetext{
${ }^{12}$ See Alichi and others (2009) for a model with endogenous policy credibility and a loss function for monetary policy.
} 
than is the case if the inflation increase is accompanied by a rise in inflation expectations. Indeed, little or no interest rate increase will be needed in response to a shock if it is expected to reverse over a relatively short period of time without having any impact on underlying inflation. Moreover, to help avoid a generalized increase in inflation expectations following an increase in a value-added tax (VAT) or retail sales tax and perhaps thereby to preclude the need for increases in policy interest rates, the central bank could emphasize that it would accommodate the first-round effects of the VAT but would respond to second-round effects. 


\section{References}

Alichi, A., H. Chen, K. Clinton, C. Freedman, M.J. Johnson, O. Kamenik, Turgut Kisinbay, and D. Laxton, 2009, "Inflation-Forecast Targeting Under Imperfect Policy Credibility," Forthcoming IMF Working Paper.

Barro, R. and D. B. Gordon, 1983a, "Positive Theory of Monetary Policy in a Natural Rate Model," Journal of Political Economy, Vol. 91 (August), pp. 589-610.

_ 1983 b, "Rules, Discretion, and Reputation in a Model of Monetary Policy," Journal of Monetary Economics, Vol. 12, pp. 101-121.

Batini, N. and D. Laxton, 2007, "Under What Conditions Can Inflation Targeting Be Adopted? The Experience of Emerging Markets," in Monetary Policy under Inflation Targeting, ed. by Frederick S. Mishkin and Klaus Schmidt-Hebbel (Chile: Banco Central de Chile), pp. 467-506.

Bayoumi, T., D. Laxton and P. Pesenti, 2004, "Benefits and Spillovers of Greater Competition in Europe: A Macroeconomic Assessment," ECB Working Paper No. 341 and NBER Working Paper No. 10416.

Bernanke, B., T. Laubach, F., Mishkin, and A. Posen, 1999, "Inflation Targeting: Lessons from the International Experience," (Princeton: N.J.: Princeton University Press).

Blanchard, O., and J. Gali, 2007, "Real Wages Rigidities and The New Keynesian Model," Journal of Money, Credit, and Banking, Vol. 39, Supplement 1, pp. 35-65.

Freedman, C., D. Laxton, and I. Otker-Robe, 2009, "On Developing a Full-Fledged Inflation Targeting Regime: Doing What You Say and Saying What you Do," forthcoming Internet Book on Inflation Targeting.

Friedman, M., 1968, "The Role of Monetary Policy," American Economic Review Papers and Procedings, Vol. 58, No. 1, pp. 1-17.

Juillard, M., 2008, “DYNARE: A Program for Simulating and Estimating SDGE Models”, http://cepremap.cnrs.fr/dynare.

Khan, M., and S. Semlali, A., 2000, “Threshold Effects in the Relationship Between Inflation and Growth," IMF Working Paper No. 00/110, available at www.imf.org.

Kumhof, M. and D. Laxton, 2007, "Improved Macroeconomic Performance-Good Luck or Good Policies” Box 5.2 of Chapter 5 of the October 2007 World Economic Outlook, International Monetary Fund, available at www.imf.org. 
Kydland, F.E., and E.C. Prescott, 1977, "Rules Rathe Than Discretion: The Inconsistency of Optimal Plans," Journal of Political Economy, Vol. 85, pp. 473-92.

Laxton, D. and P. N'Diaye, 2002, "Monetary Policy Credibility and the Unemployment-Inflation Nexus: Some Evidence from Seventeen OECD Countries," IMF Working Paper 02/220, available at www.imf.org.

Longworth, D., 2002, "Inflation and the Macroeconomy: Changes from the 1980 to the 1990s," Bank of Canada Review (Spring).

Lucas, R.E., 1976, "Econometric Policy Evaluation; A Critique," Carnegie-Rochester Conference Series on Public Policy, Vol. 1, pp. 19.46.

Mishkin, F., 2007, "Can Inflation Targeting Work in Emerging Market Countries?" C. Reinhart, C. Vegh, and A. Velasco, eds.,Capital Flows, Crisis, and Stabilization: Essays in Honor of Guillermo Calvo, MIT Press.

Phelps, E.S., 1968, "Money Wage Dynamics and Labor Market Equilibrium," Journal of Political Economy, Vol. 76 (4, Part 2), pp. 678-711.

Roger, S. and M. Stone, 2005, “On Target? The International Experience with Achieving Inflation Targets," IMF Working Paper No. 05/163, available at www.imf.org.

Rogoff, K., 1985, "The Optimal Degree of Commitment to an Intermediate Target," Quarterly Journal of Economics, Vol. 100, pp. 169-90.

Sargent, T.J., 1971, "A Note on the 'Accelerationist' Controversy," Journal of Money, Credit, and Banking, Vol. 3, pp. 721-25.

Stock, J. and M. Watson, 2003, "Has the Business Cycle Changed? Evidence and Explanations," Federal Reserve Bank of Kansas City Symposium on Monetary Policy and Uncertainty: Adapting to a Changing Economy, August.

Stone, M.R., 2003, "Inflation Targeting Lite," IMF Working Paper No. 03/12, available at www.imf.org

Svensson, L., 1997, "Inflation Forecast Targeting: Implementing and Monitoring Infaltion Targets," European Economic Review, Vol. 41, No. 6, pp. 1111-46.

Taylor, J., 1993, “Discretion Versus Policy Rules in Practice,” Carnegie-Rochester Conference Series on Public Policy, Vol. 39, pp. 195-214. 
1996, "How Should Monetary Policy Respond to Shocks While Maintaining Log-Run Price Stability - Conceptual Issues," in Federal Reserve Bank of Kansas City, Achieving Price Stability, pp. 181-95 (Kansas City: Federal Reserve Bank of Kansas City).

_ 1998a, "A Historical Analysis of Monetary Policy Rules,” in Monetary Policy Rules, ed. by J. B. Taylor (Chicago: Chicago University Press).

_, $1998 b$, “The Robustness and Efficiency of Monetary Policy Rules as Guidelines for Interest Rate Setting By the European Central Bank,” IIES Seminar Paper No. 649.

—_ 1999, Monetary Policy Rules, (Chicago: University of Chicago Press).

The Economist, 2006, "Big Questions and Big Numbers-Economic Models," Special Report, (July), pp. 67-69.

Walsh, C. 1995, "Optimal Contracts for Central Bankers," American Economic Reviwe, Vol. 85, No. 1 (March), pp. 150-67.

__ 1998, "Monetary, Theory, and Policy," (Cambridge, MA: MIT Press). 